\title{
The Strategy of Hong Kong-Zhuhai-Macao Economic Integration Development under the Background of Hong Kong-Zhuhai-Macao Bridge
}

\author{
Yang Song \\ Zhuhai College of Jilin University \\ Zhuhai, China
}

\begin{abstract}
The opening of the Hong Kong-Zhuhai-Macao Bridge plays an extremely important role in promoting the economic integration of Hong Kong, Zhuhai and Macau. Based on the "core-peripheral" theory, Hong Kong with its high capital use efficiency, rapid material transport capability and leading wage income levels will gather more resource elements from Zhuhai and Macau, while Zhuhai and Macau will accept the core area (Hong Kong) for radiation and promotion and obtain a certain degree of technological diffusion, business service concept innovation and business management mode transformation; the Hong Kong-Zhuhai-Macao Bridge has accelerated the people flow, material flow, capital flow and other factor flows in Hong Kong, Zhuhai and Macao and has become the backbone of foreign trade; deepening the industrial division and cooperation of Hong Kong, Zhuhai and Macao to complement and benefit each other; and establishing a benefit balance mechanism in Hong Kong, Zhuhai and Macao.
\end{abstract}

Keywords-economic integration; Hong Kong-Zhuhai-Macao bridge; development strategy

\section{INTRODUCTION}

In recent years, a number of city areas with integration trends have gradually formed in our country, e.g. the Bohai Economic Circle, the Yangtze River Delta Economic Circle, the Changsha-Zhuzhou-Xiangtan Urban Agglomeration, the Wuhan City Circle and so on. These economic circles use geographical advantages to bring several administrative regions together to form a closely linked regional community in economics, politics and the livelihood. To be precise, its development thought and theoretical basis are all derived from the regional economic integration theory in regional economic theory. Throughout the macroeconomic situation at home and abroad, developed countries are faced with a series of problems such as economic slowdown, European debt crisis, rising unemployment and trade protectionism, therefore the regional economic integration is undoubtedly the best choice for huddling to warm, sharing current difficulties, turning crisis into opportunities and leaping development.

As economic growth mode changes and regional competition awareness deepens, the idea of regional economic integration development has gradually become an important means and method for solving regional economic development problems and plays an important and significant role specially in solving imbalanced regional economic development and economic development lack strength caused by the exhaustion of resources in the region as well as promoting regional overall competitiveness. The theory of regional economic integration first appeared in western Europe in the 1940s. The customs union theory which is the core part of regional economic integration theory was marked by the publishing of Customs Union Issues in the 1950s by the American economist Vaina. Since the 1990s, as the international market competition was getting fierce and trade protectionism was rising, regional economic integration has formed an unstoppable trend and has become a new bright spot for industrialization, urbanization and informationization. The development idea of regional economic integration is to create a broader and larger integrated economy with decentralized economies with certain linkages. It requires the constituent parts should have a certain degree of complementarity and form a reasonable industrial division and cooperation and all kinds of resource elements in the region can flow freely at low cost or even zero cost to form optimal allocation and reasonable sharing of resources and elements, and optimizing and integrating regional industries, markets, resources and management to form interregional division and cooperation so as to achieve the best efficiency and optimal results for regional economic development. The essence is to intensify mutually beneficial cooperation and reduce the losses caused by unreasonable competition, thus the overall competitiveness of the integrated region can be enhanced. The Hong Kong-Zhuhai-Macao Bridge has provided a direct land route between Hong Kong, Zhuhai and Macau across the ocean. This great project has shortened the distance between Hong Kong, Zhuhai and Macao, making the traffic between the three places more convenient. The communication can be more convenient and quick for residents, laying the foundation for the future economic integration of Hong Kong, Zhuhai and Macao, and increasing the weight of regional economic integration.

\section{GUIDING SIGNIFICANCE OF "CORE-PERIPHERY"} THEORY IN THE INTEGRATION DEVELOPMENT OF GUANGDONG, HONG KONG AND MACAO

The "core-peripheral model", which is also known as the "core-periphery" theory or the "center-periphery" theory, is a spatial polarization theory developed by Friedman using 
Schumpeter's innovative ideas, which belongs to the content of the imbalanced economic growth theory system. The theory points out that due to the differences in regional natural resources and other conditions, certain regions will develop into the "core" due to various reasons, while other regions are "peripheral" due to slow development, and there is an unbalanced development relationship between the two. The core area generally refers to areas with developed economy, abundant capital, high technological level, concentrated population and rapid economic growth. The periphery area generally refers to areas with relatively backward economic development, slow economic growth, lack of innovation ability and weak competitiveness. The core area is a regional social organization system with higher innovation and transformation capabilities. While the periphery area is a regional social subsystem determined by the core social area based on the dependency relationship with the core area. The core area and the periphery area have formed a complete space system, in which the core area occupies a dominant position in the space system. The core area can be divided into the transitional area and the resource frontier area. The transitional area can be further subdivided into the upper transitional area and the lower transitional area ${ }^{1}$. The upper transitional area refers to the development corridor connecting two or more core areas. Although located in the outer side of the core area, it is connected to the central area and establishes a certain degree of economic links with it, in which the economic development, employment and people's livelihood are strongly affected and radiated by the core area, with possibilities of forming ancillary or secondary core areas. The lower transition area refers to areas where the industry is aging and loosely connected to the core area due to various reasons, making its economic development slower or tending to stagnation. The resource frontier area refers to those that are far away from the core area, but have abundant resources and take advantage of new economic growth points, with possibilities of developing into a secondary core area. With the development of economy, the spatial structure of the core area and the periphery area is not fixed, and the core area influences the periphery areas in terms of capital, technology, etc., and forms a spatial diffusion effect. This diffusion effect will be attenuated as the distance increases. Therefore, the periphery area closer to the core area is more affected by the diffusion effect. The core area spreads to the secondary core area, and the secondary core area spreads to the periphery area. With the government intervention, interregional population migration, market expansion, improvement of transportation conditions and the proliferation of cities, the boundaries between the core and the periphery will become more and more blurred and then disappear. The economy of the entire region will be changed from unbalanced to balanced. Finally the regional economic integration will be achieved. $^{2}$

In terms of the economic development levels of Hong Kong, Zhuhai and Macau, Hong Kong's economic level and speed of development are much higher than those of Zhuhai

Wang Yuming. Core- periphery Geographical Theory in Regional Tourism Planning [J]. ECONOMIC GEOGRAPHY, 2002(3): 372-375.

Hou Xiaoli Study on Regional Process and Development Model in the Peripheral Region [M] China Market Press, November 2007. and Macau. In particular, there is a large gap between Zhuhai and Hong Kong, and this kind of urban agglomeration structure is in line with the "core-peripheral" research model in regional economic theory. The "core-peripheral model", also called the "core-periphery" theory or the "center-periphery" theory, is a spatial polarization theory developed by Friedman using Schumpeter's innovative ideas, which belongs to the content of the imbalanced economic growth theory system. The theory points out that due to the differences in regional natural resources and other conditions, certain regions will develop into the "core" due to various reasons, while other regions are "peripheral" due to slow development, and there is an unbalanced development relationship between the two. The core area generally refers to areas with developed economy, abundant capital, high technological level, concentrated population and rapid economic growth. The periphery area generally refers to areas with relatively backward economic development, slow economic growth, lack of innovation ability and weak competitiveness. The core area is a regional social organization system with higher innovation and transformation capabilities. While the periphery area is a regional social subsystem determined by the core social area based on the dependency relationship with the core area. The core area and the periphery area have formed a complete space system, in which the core area occupies a dominant position in the space system. The core area can be divided into the transitional area and the resource frontier area. The transitional area can be further subdivided into the upper transitional area and the lower transitional area. The upper transitional area refers to the development corridor connecting two or more core areas. Although located in the outer side of the core area, it is connected to the central area and establishes a certain degree of economic links with it, in which the economic development, employment and people's livelihood are strongly affected and radiated by the core area, with possibilities of forming ancillary or secondary core areas. The lower transition area refers to areas where the industry is aging and loosely connected to the core area due to various reasons, making its economic development slower or tending to stagnation. The resource frontier area refers to those that are far away from the core area, but have abundant resources and take advantage of new economic growth points, with possibilities of developing into a secondary core area ${ }^{3}$. With the development of economy, the spatial structure of the core area and the periphery area is not fixed, and the core area influences the periphery areas in terms of capital, technology, etc., and forms a spatial diffusion effect. This diffusion effect will be attenuated as the distance increases. Therefore, the periphery area closer to the core area is more affected by the diffusion effect. The core area spreads to the secondary core area, and the secondary core area spreads to the periphery area. With the government intervention, interregional population migration, market expansion, improvement of transportation conditions and the proliferation of cities, the boundaries between the core and the periphery will become more and more blurred and then disappear. The economy of the entire region will be changed from unbalanced

\footnotetext{
Wang Yuming. Core-periphery Geographical Theory in Regional Tourism Planning [J]. Economic Geography, 20029(3): 372-375
} 
to balanced. Finally the regional economic integration will be achieved $^{4}$.

In Hong Kong-Zhuhai-Macau city groups, Hong Kong is the "core area" and Macao is the "secondary core area", while Zhuhai is the "periphery area". According to the "coreperiphery" theory, Hong Kong will be more dominant in the economic interaction with Zhuhai. Under the help of the Hong Kong-Zhuhai-Macao Bridge, Hong Kong with high capital use efficiency, rapid material transfer capability and leading wage income levels will surely gather more resource elements from Zhuhai and Macau, and Hong Kong's advantages in trade, commerce and service industries will be further strengthened, thus the spatial structure of the "core-periphery" of the region would be enhanced, and the core position of Hong Kong would be further consolidated and the economic development level would be further improved. Zhuhai will accept the radiation and driving effect of the core area (Hong Kong). It will mainly undertake the manufacturing industrial transfer from Hong Kong and inherit the tradition of Shenzhen to form a new model of "front shop and back factory". Not only that, Zhuhai can obtain a certain degree of technology diffusion, business service concept innovation and business management mode transformation.

\section{HONG KONG-ZHUHAI-MACAO BRIDGE Is THE AORTA FOR RAPID CIRCULATION OF REGIONAL ELEMENTS}

The ideal state of regional economic integration is that the labor, material, capital, technology, information and other production factors in the region can flow freely. Factor flow is the way to optimize the allocation of resources. The lower the flow cost, the stronger the factor is in promoting regional economic development. Under the conditions of a market economy, these factors of production will flow to the locations where the maximum economic benefit can be generated, thereby stimulating the optimization of resource allocation in the region and maximizing economic efficiency. Under the conditions of external forces with no administrative division restrictions, according to the "comparative advantage theory" and the "invisible hand" of market mechanism, resources and elements will flow naturally, orderly and efficiently to various industries within the region. This is an ideal state. It requires that the region have sound laws and regulations that can restrict and regulate market orders; market entities should be "economic people" and "rational people"; there is no narrow local interest protectionism in the region. However, under our present administrative system, this ideal state is difficult to be achieved. Local interest is a key factor hindering regional integration. Finding cooperation areas of mutual benefit and establishing an interest balance mechanism are a prerequisite for cooperation.

Obviously, the Hong Kong-Zhuhai-Macao Bridge has shortened the distance between Hong Kong, Zhuhai and Macau, reduced logistics costs and improved the efficiency of factor circulation. Under the conditions of a market economy, these factors of production will flow to the locations where the maximum economic benefit can be generated, thereby

Hou Xiaoli Study on Regional Process and Development Model in the Peripheral Region [M] China Market Press, November 2007. stimulating the optimization of resource allocation in the region and maximizing economic efficiency. Under the conditions of external forces with no administrative division restrictions, according to the "comparative advantage theory" and the "invisible hand" of market mechanism, resources and elements will flow naturally, orderly and efficiently to various industries within the region. This is an ideal state. It requires that the region have sound laws and regulations that can restrict and regulate market orders; market entities should be "economic people" and "rational people"; there is no narrow local interest protectionism in the region. Although Hong Kong, Macao and Zhuhai are in different social systems of "one country, two systems", developing free trade and following the principles of market economic development are the common characteristics and aspirations of the three places; sharing needed products, improving production efficiency and reducing production costs are the common choices of the three places. After the completion of the Hong Kong-Zhuhai-Macao Bridge, the flow of elements in Hong Kong, Zhuhai, and Macau will become more closely related and the governments of the three places should not obstruct it but instead should strongly support it. From the perspective of production factors flow theory, it can be predicted that Hong Kong will gain greater benefits in the first few years after the completion of the Hong Kong-Zhuhai-Macao Bridge, and more people flow and material flow will gather in Hong Kong which will further promote the development of Hong Kong's retail, service, tourism and logistics.

\section{Hong Kong-Zhuhai-Macao BRIDGE WiLl Promote REGIONAL DIVISION AND COOPERATION BETWEEN HONG KONG, ZHUHAI AND MACAO}

The construction of the Hong Kong-Zhuhai-Macao Bridge will promote the regional division and cooperation between Hong Kong, Macau and Zhuhai, as well as be a springboard for economic exchanges and cooperation between Hong Kong and the entire western region of Pearl River Delta. Although compared with Macau and Zhuhai, Hong Kong's economy is more developed, but facing increasingly fierce market competition from neighboring Southeast Asian countries such as Japan, South Korea and Singapore, Hong Kong's leading advantage and regional competitiveness is declining. Resource constraints and rising factor prices have prompted Hong Kong to urgently upgrade its industries and seek wider development space and partners. At present, Hong Kong's pillar industries include the financial industry, business services, logistics and tourism. Hong Kong's major industrial upgrading and transformation methods are the spread of processing and manufacturing to the Mainland and complementing the advantages of the Mainland. In the past, due to geographical factors, they mainly spread to the east of the Pearl River estuary. However, at the current stage, the production prices of factors of production on the east bank of the Pearl River estuary are also increasing rapidly and the product market is becoming saturated. As a result, the need to promote links and economic cooperation with the western region of the Pearl River Estuary and the expansion of the mainland market are gradually emerging. The economic development of Macao is mainly restricted by the narrow geographic area and the monotonous industrial structure. Macau's population density is 
high but its labor force quality is low. Its pillar industries mainly include gaming, tourism, finance and real estate, among which the gaming industry's output value is the highest, accounting for more than half of gross domestic production. The advantages brought by the gaming industry to Macau are mainly reflected in the increase of city awareness and extensive contact with the international market. Macao has a close economic tie with Hong Kong and has introduced a large amount of capital, talent, technology and information from Hong Kong to develop the local economy. Therefore, Hong Kong and Macao have already had relatively perfect industrial division and cooperation. At present, the costs of land and labor in Hong Kong and Macao are high, and the structure and layout of transportation networks between regions is not reasonable, which can not meet the needs of upgrading regional economic and industrial structures. The construction of the Hong Kong-Zhuhai-Macao Bridge will deepen the industrial division and cooperation between Hong Kong, Zhuhai and Macao, and complement each other for mutual benefit. As the bridge will greatly shorten the distance between Zhuhai and Hong Kong, the relatively cheap labor force and land and the complementary industrial structure with Hong Kong in the west bank of the Pearl River Estuary will attract more investment, which will be conducive to a new round of adjustment of industrial structure and create conditions for the continued prosperity and stable development of the region. Utilizing Zhuhai's resources and markets can reduce the economic costs of the investment and production operations of Hong Kong and Macao manufacturers, and expand the demand of product market. Using the advantages of Hong Kong's finance, trade, information and management technologies can provide financial channels for the economic development of Zhuhai, introduce information management technology and develop the international marketing market. Macau's tourism industry is mature and has significant advantages. Zhuhai and Macau use Hengqin area as an experimental field for regional cooperation to establish an international leisure tourism industry park, deepen tourism cooperation between Zhuhai and Macau and jointly improve the competitiveness of tourism in the two places and expand overseas market and accelerate Zhuhai's pace of integrating with the world market.

\section{ESTABLISHING THE INTEREST BALANCE MECHANISM BETWEEN HONG KONG, ZHUHAI AND MACAO}

The core and foundation for the establishment of regional economic integration is the formation of a common interest balance mechanism in the region. The so-called "common interest balance mechanism" means that all countries or administrative regions within the region can form a full division and cooperation in the process of economic integration and obtain the win-win result of resource sharing and benefit sharing, which not only enhances the overall competitiveness of the entire region in the integration process, but also enables all members to improve their respective economic and social benefits. The essence of regional economic integration, whether it is cross-border or crossadministrative, is to form regional common interests on the basis of rational division and full cooperation. This common interest not only can be shared by all economic entities in the region, but also is the common pursuit of administrative entities in the region ${ }^{5}$. The key to form regional common interests is to find a "balance point" that meets the interests of all parties. However, in the process of seeking regional economic integration, certain members will inevitably cut off some uncompetitive industries and lose certain economic benefits, while other so members will gain more economic benefits for their relative advantages. At this point, "balance" has been broken. To reshape the "balance", it is necessary to establish an "interest compensation mechanism". This process often requires a long time and a constant running-in phase.

\section{CONCLUSION}

From the beginning of the construction of the Hong KongZhuhai-Macao Bridge, Hong Kong, Zhuhai, and Macau have been gradually running in and deepening cooperation to create a regional cooperation information platform for Hong Kong, Zhuhai and Macao based on this and to improve the cooperation and promotion mechanism of regional information projects. Explore and establish project cooperation models jointly invested and guided by Hong Kong, Zhuhai and Macao, formulate joint development of regional informatization projects, determine the benefits distribution, cooperation mechanisms and implementation methods for cooperative projects, and ensure smooth implementation of cooperative projects; explore cross-regional coordination and promotion mechanism for major information infrastructure, establish a regional coordination system for major project annual promotion plans, starting with the key links of project establishment, approval, construction, inspection, acceptance, operation and maintenance, strengthen communication and coordination, establish mutual notification and information sharing system and improve the overall anti-same capability and overall efficiency of the project.

\section{REFERENCES}

[1] Wang Yu- ming. CORE-PERIPHERY GEOGRAPHICAL THEORY IN REGIONAL TOURISM PLANNING [J]. ECONOMIC GEOGRAPHY, 2002(3): 372-375

[2] Friedman J R. Regional development policy: a case study of Venezuela M]. Cambridge:MITPress. 1966.

[3] The Transportation Planners Council of ITE. Traffic Access and Impact Studies for Site Development. ITE Journal,1988(8):17-24.

[4] Krugman P. Increasing Returns and Economic Georaphy[J]. Journal of Political Economy, 1991, (99).

[5] Soumya S. DEY and Jon D. Fricker. Traffic Impact Analysis and Impact Fees in State Departments of Transportation. ITE Journal,1994(5):39-44.

[6] Florida Department of Transportation. Site Impact Handbook [R].Tallahassee: Florida Department of Transportation, 1997.

Cheng Gong. Research on Regional Economic Integration of Central Henan Urban Agglomeration [M]. Intellectual Property Press. January 2008 